\title{
Political discourse approach applied the current study issue occurred
}

\author{
Gloria Monica Woodlove \\ Colgate University, New York, Northeastern United States \\ Mike Emerson Vurly \\ Colgate University, New York, Northeastern United States
}

\begin{abstract}
The research was to aim at approaching a political discourse as an effort to solve the issues. News reporting assigns meaning to issues by providing a continuous record of public events and visibility to the claims of actors. The public sphere is an important field where social problems are constructed and political alternatives become defined. When one considers these functions, it is hardly surprising that news has become an important source of data for a group of researchers who are interested in studying the nature of political challenges that are mobilized in the public domain. However, there sometimes appears to be a tendency within the social movements field to let theoretical development outrun a discussion on the methods with which we are equipped to address our research questions. In this contribution, our focus will be self-consciously directed to methods, and more precisely we make specific proposals regarding how the important methodological developments that have been made in the field in recent times, might be profitably extended.
\end{abstract}

Keywords---discourse, domain, method, politics, social.

\section{Introduction}

The second school of methods that use news data and other written document sources for studying social movements is political discourse analysis. Political discourse analysis is associated with the constructivist framing perspective and is perhaps best represented by the work of Gamson and his collaborators (Gamson 1988, 1992; Gamson \& Modigliani 1989; see also Gitlin 1980, Donati 1992). This approach looks at how movement actors attempt to challenge dominant definitions of political reality by mobilizing new interpretations -schemata, frames- of contested social relationships, and making them visible in the public sphere. Whereas protest event analysis takes protest as an indicator for the level of challenges to the political system, political discourse analysis takes the emergence and public visibility of movement "frames" as an indicator for the "meaning contents" of challenges to dominant political and cultural norms. The two approaches focus on different dimensions of collective challenges to political power: the first relating an action type variable -"protests"- to institutional political opportunities, and the second relating an interpretative scheme variable -"frames"- to the dominant sets of cultural and political norms (Hu \& Cao, 2011; Mur-Dueñas, 2011).

Linguistics and Culture Review (C) 2017.

Corresponding author: Gloria M. Woodlove, woodlove@colgate.edu Received 09 February 2017 / Accepted 27 May 2017 / Published 18 June 2017 
Proceeding from a critique of the explanatory limitations of protest event analysis, and what has been learned from experiences with this method over the last decade, we present some of the benefits that we argue can be gained from extending the approach. The examples we present in the second part of the paper are drawn from a current project on Mobilization on Ethnic Relations, Citizenship, and Immigration (MERCI). In designing this internationally comparative project, we explicitly set out to move beyond a protest event design, firstly, by systematically coding discursive dimensions, so that the focus shifted from "protest" to „political claims-making“, and secondly, by coding all actions by all actors which are relevant to our political issue field, so that the focus shifted from "movement" to "multi-organizational field“ (Curtis \& Zurcher 1973; Ahl \& Nelson, 2015; Aijmer \& SimonVandenbergen, 2004). Substantive topical research from this project has been published elsewhere, on both comparative and national aspects. Here, the substance of our topic will be referred to only where it is necessary for demonstrative purposes.

\section{A model for the analysis}

The model which we present here for the analysis of pragmatic markers draws upon concepts developed in pragmatics and anthropological linguistics to explain the anchoring of utterances in the discourse context. What has been lacking in the literature so far, however, is an explicitation of how these different concepts can be usefully brought together to account for the existence and use of pragmatic markers. In this section, we shall elucidate a possible way of combining various concepts to form a model that has explanatory power.

Two aspects that are crucial to pragmatic markers are reflexivity and indexicality. Reflexivity, referring to the potential of language to reflect upon itself, has come to be recognized as fundamental to communication. Its crucial role was stressed by Harris (1996). Linguistic reflexivity is a far more pervasive feature of verbal communication than can be accounted for by postulating a special class of expressions (i.e. names of words, sentences, etc.) endowed with the unlikely property of being isomorphic with what they designate. Linguistic reflexivity derives from our whole engagement in language as communicators.

\section{Discussion}

Verschueren (2000) argues along the same lines, saying that the concept of reflexivity would be rather uninteresting if it were restricted to explicit language about language. Verschueren (2000) further defines reflexive or metapragmatic awareness as the "selfmonitoring" by language users which "at whatever level of salience, is always going on" and claims that "there is no language use without a constant calibration (to use Silverstein's term) between pragmatic and metapragmatic functioning". The range of explicit indicators of metapragmatic awareness includes discourse markers or pragmatic markers. Thus such words as of course, actually, in fact explicitly indicate the speakers' awareness of the communication process as taking place in a context and thereby help to shape that process in a particular way.

Such words are "identifiable linguistic traces" (Verschueren, 2000; Soler, 2002; Upton \& Connor, 2001) of self-monitoring at a fairly high level of consciousness or salience. The reflexive property of pragmatic markers explains their core role in structuring ongoing discourse in that speakers, by using them, show an awareness of how their utterances fit in with preceding or following discourse. It is clear, however, as emphasized by various authors (e.g., Verschueren, 2000; Mertz \& Yovel, 2000) that metapragmatic indicators not merely refer to aspects of the context but also alter it (see Silverstein, 1976 on the distinction between presupposing and creative language forms). 
The context in this view is a cognitive phenomenon; it can be identified with the mental states (what is known or believed) which the interlocutors bring on-line in the interaction. The negotiation of meaning in the communication situation involves the continual updating of these assumptions, which may be explicit or only assumed, for example by challenging them or denying them. Pragmatic markers encode information that is necessary in order to constrain or guide the interpretation process. For example, in fact signals a contrast with a previous claim or strengthens what has been said.

The second feature that has been assigned to pragmatic markers is indexicality. It refers to the property of linguistic forms to point to one or several situational dimensions. Ochs (1996) distinguishes, apart from the temporal and spatial locus of the communication, the following situational dimensions: social identity, social act, activity, affective stance, epistemic stance. She points out that the latter two stance types are "encoded at many levels of linguistic structure", including phonology, lexicon, and grammar. It is within the dimension of epistemic stance, as defined in Chafe \& Nichols (1986) that pragmatic markers of expectation figure as indices. Chafe (1986) is rather vague in his characterization of such devices, simply claiming that they "signal expectations of some kind, against which knowledge may be matched." That Chafe's account of evidentiality is purely in terms of attitudes to knowledge (degrees of speakers' certainty, source of knowledge, mode of knowing) seems to restrict the use of evidential to contexts in which speakers are concerned with exchange of information and to speakers' endeavors to be explicit about the truth value of their propositions.

Chafe's truth-functional view of modality and evidentiality is criticized by White $(2000$, 2003), who argues that speakers make use of these systems for various reasons which go beyond their assessment of their own or the hearers' knowledge. White proposes a model of 'engagement', i.e., systems by means of which speakers express how they engage with their utterances; 'engagement' includes the systems of modality and evidentiality (among many other linguistic forms) as ways in which speakers position themselves vis-a'-vis other, real or imagined, voices. Bakhtin's notion of heteroglossia is thus invoked to account for the fact that linguistic choices reflect either speakers' explicit recognition or denial of the existence of other, possibly divergent discourse (White, 2000, 2003; Fetzer \& Johansson, 2010; Fidel, 2008).

This perspective is a useful addition to Chafe's view on epistemic stance and particularly enlightening for an account of pragmatic markers (see Aijmer et al., in press). It explains that pragmatic markers such as of course can be used for a variety of functions including persuasion, seeking solidarity or expressing politeness (Simon-Vandenbergen \& Aijmer, 2002- 2003). It also explains how the reflexivity markers not merely reflect but actually create the context. Speakers may for instance use of course not because they think ('knowledge') that something is certain and known by the hearer but because they wish to argue that it is, thereby creating a situation in which the hearer is pushed into a particular role (Holmes, 1988; Simon-Vandenbergen, 1992; Simon-Vandenbergen \& Aijmer, 20022003).

\section{Enlarging the semantic field}

The mirror translations bring other words into the picture. Apart from the obviously related words such as as a matter of fact, in actual fact, the fact is, we get items in the field of epistemic certainty/emphasis such as certainly, definitely and the emphatic do. This shows the relatedness of epistemic modality to expectation. In addition, we get adverbs such as especially, simply, literally, which points to the relatedness of expectation markers to meanings of so-called 'particularizers' with the function of restricting the application of the utterance predominantly to the part focused on (Quirk et al., 1985; Doloreux \& Parto, 2005; Fairhurst \& Uhl-Bien, 2012) speakers reject one application and put another application in its place, emphasizing the appropriateness of the latter. There is also 
evidence for the causal meaning (since you see) and for dismissive meaning (in any case, anyway).

The final goal of the exercise is to construct a field or a 'semantic map' of expectation on the basis of translations. Highly similar meanings should be close together in the field and remote meanings further away from each other. From a translation perspective, we could say that, for example, if in fact is translated in two different ways in the corpus we can assume that these ways represent different meanings.

If the items resulting from the first mirroring (i.e., in this case, the Dutch and Swedish translations of the English items) are translated back in the same way, we can assume that these meanings are similar. If the forms resulting from the first mirroring have different back translations, they are farther apart in meaning. Moreover, if a particular meaning or function of a word is rendered in more than one language, this is strong evidence of the importance of this meaning.

Translations are thus used as tools to establish lexical fields in all languages concerned. These fields, in their turn, then serve as a tertium comparationis for contrastive analysis. The equivalents can be further analyzed in more detail, going from form to function. In other words, the information can be used as the basis for an in-depth analysis of crosslinguistic correspondences and to describe associations between form and function which are only hinted at in the lexical fields.

\section{The use of corpora and discourse studies}

The use of methods associated with CL in order to carry out CDA is not a novel practice (Krishnamurthy, 1996; Stubbs, 1994), particularly given that both CL and CDA are relatively new movements in linguistics. Overall, the number of such studies in proportion to the number of studies in CL or CDA is extremely small. However, more recently, it seems that the use of CL techniques is becoming increasingly popular in critical approaches to discourse analysis. A case in point is a recent relevant edited collection (Fairclough et al., 2007), in which almost one in five articles is informed by corpus analysis.

Although the utility of using CL approaches in CDA and related fields has already been demonstrated (Baker, 2004a, 2006; Hardt-Mautner, 1995; Koller \& Mautner, 2004; Mautner, 2000; O'Halloran and Coffin, 2004), it must also be noted that, in most such studies, the use of methods and theoretical frameworks traditionally associated with CDA and CL has not been balanced. Corpus-based studies may adopt a critical approach, but may not be explicitly informed by CDA theory and/or its traditional methods, or may not aim to contribute to a particular discourse-oriented theory (Krishnamurthy, 1996; Stubbs, 1994). Similarly, studies aiming to contribute to CDA may not be readily identifiable by corpus linguists as being corpus-based/driven (Fairclough, 2000; Kovács \& Wodak, 2003; Wodak et al., 1990), except for the seminal research by Gerlinde Mautner in the 1990s.

Overall, the latter type of study tends to make limited or casual use of a corpus or corpusbased techniques. Sometimes, the corpus is used as a repository of examples (Flowerdew, 1997), as opposed to the analysis adhering to the 'principle of total accountability' (Leech, 1992), that is, accounting for all the corpus instances of the linguistic phenomena under investigation. CDA studies making use of corpora have, in general, tended to avoid carrying out quantitative analyses (see also Stubbs, 1997), preferring to employ concordance analysis (Magalhaes, 2006).

\section{Policy Learning}

Recent research on Europeanisation distinguishes between 'absorption' or simple institutional learning (that is, learning limited to coping mechanisms) and 'transformation' 
or, in international relations language, thick learning, which takes place when institutions move on to a different logic of political behavior. Thick learning effects lead to what has been described in various guises as reflexive understanding (Dobuzinskis 1992), deutero learning (Bateson, 1973), or institutional development (Laird, 1999).

There are two difficulties raised by the analysis of simple learning versus institutional development. One problem is that to cast the discussion of Europeanisation exclusively in terms of its effects (simple learning or institutional development) presupposes that there are effects. Put differently, there is a serious risk of prejudging the significance of European Union (EU) policy, whether in terms of the constraints it generally places on member states or in terms of its effects on those member states. Any consideration of EU decisions shows that the decisions themselves have very different rules for compliance (see Schmidt, 2002c), from highly specified rules that countries are required to follow to the letter (e.g., the Maastricht criteria in the run-up to EMU or certain kinds of environmental standards); to less specified rules that countries have more leeway in following (e.g., the regulatory regimes for telecommunications or electricity); to suggested rules (e.g., in the European Employment Strategy or in tax competition - Radaelli, 2003b); to no rules at all, as in mutual recognition. This means that EU policies themselves exercise different degrees of institutional pressure for change in member states.

Moreover, whatever the compliance rules, EU decisions generally have a very different impact in any given country, depending upon the mediating factors outlined above. Where EU policy poses a significant problem for a polity, by challenging long-standing policy legacies and long-held preferences, it can be useful to analyse its effects in terms of policy learning, whether simple learning - because policy actors resort to coping mechanisms, and respond with inertia to the pressures - or thick learning - because transformation occurs, with the EU policy serving to alter national policy as it galvanizes new interest coalitions and empowers some actors as opposed to others (Héritier, 2001). However, where the EU policy poses only a minimal problem, because of the goodness of fit between the EU policy and national policy legacies and preferences, analysis in terms of learning is not very useful, since absorption of the EU policy is the natural outcome, and 'simple learning' the only reasonable response. This was clearly the case of Germany in terms of European monetary integration and of the UK with regard to telecommunications and immigration policy.

Another problem with the focus on the effects of EU decisions is that it may lead the researcher to adopt a top-down logic in which the only aim is to find out the domestic effects of independent variables defined at the EU level. In this top-down perspective, the problem of domestic policy-makers is all about putting into practice European policy. This is a managerial, chain-of-command logic. By contrast, we would argue for an 'inside-out' or 'bottom-up' perspective (Radaelli, 2003a).

This can be done in a variety of ways. One possible way is the one outlined above through a consideration of the mediating factors involved in policy adjustment, including the policy problems, policy legacies, policy preferences, political-institutional capacity and discourses of actors confronted with a particular EU decision and a given set of compliance rules. But this approach is still somewhat tainted by the top-down perspective, since it takes the EU decision as the point of departure of the study (to avoid saying independent variable'), and what happens at the domestic level as following from that decision, whereas the process is much more complex, given among other things the involvement of national actors in the EU decision itself, as part of the process of European integration.

Another approach is more historical, by tracing temporal sequences to show when key decisions were made (time), the sequences of decisions (timing) and the speed (tempo) (Dyson, 2002). Institutional development is a process, not a single episode in time. The implication is that one should seek to trace sequences of events in policy adjustment and, 
drawing upon Elmore's suggestions for bottom-up research, look at the individual and institutional choices 'that are the hub of the problem to which policy is addressed, to the rules, procedures, and structures that have the closest proximity to those choices, to the policy instruments available to affect those things' (Elmore, 1981). With this 'bottom-up perspective' on Europeanisation, one can, for example, see if and when EMU played a role in the logic of national economic policy-making - or even changed this logic (Radaelli, 2002).

\section{Discourse analysis as method}

Discourse analysts use many different ways of organizing and analyzing data (see Winther Jørgensen \& Phillips, 2002; Wodak \& Meyer, 2009; Wood \& Kroger, 2000), often starting from a content analysis. What distinguishes discourse analysis, however, from ordinary content analysis is the way in which the material is interrogated: the analysis focuses not only on what the content is but also on what it does; what is included and what is not; what is implied and what is asserted. In other words, it looks at its data as productive rather than representational.

In our study, we proceed empirically with an analysis framework based on Foucault's theories as developed by Ahl (2007a). Foucault defined discourses as "practices which systematically form the object of which they speak" (Foucault, 1972a). The first task is thus to decide what the object is. In our case it is women, women entrepreneurs, or women's entrepreneurship. Foucault further details certain discursive practices that uphold a discourse. These become central organizing tools of the method. The first and foremost of these discursive practices are assumptions that are taken for granted. Sometimes such assumptions can be clearly identified directly in text, but more often they must be inferred from the narrative record. In this research we look for assumptions embedded in the motivations to develop and implement policy on women as entrepreneurs and on their ventures.

A second discursive practice is that which is excluded, that which cannot be said, that which is not said. This comes about because of choices made and because of embedded assumptions, intentional and assumed. To identify these practices, a comparative research structure is valuable. By investigating how the policy record compares across countries, we can recognize what is obvious in one and absent in the other, how discourse is nuanced, as well as what is absent in both.

A third discursive practice, embedded throughout this research, is the role of institutional support. The examination of this practice is implied in our research design in that we examine policy writings. We are also interested in how institutional discourse changes over time; hence our longitudinal study of policy documents. Here, changes in assumptions and exclusions are viewed over a 20-year period.

Being in a relatively early stage of development as the third research approach, MMR scholars still face open questions and are discussing many basic issues related to the approach. Most central to the MMR community are the various definitions for the approach. Although most leaders in the field agree that MMR mixes qualitative and quantitative approaches (Johnson et al., 2007), this understanding is not shared by all.

Axinn \& Pearce (2006), for instance, present MMR strategies for data collection and focus on the instruments used for this purpose. They explain that it is not useful to label data collection on its own as qualitative or quantitative because data collected by any instrument-including observation and conversational interview-can be analyzed quantitatively. They define MMR as the mixing of highly structured instruments for data collection with much less structured ones. 
Axinn \& Pearce (2006) view of MMR points to another theme that differentiates MMR definitions: In which stage of a research project should mixing occur to qualify as MMR? Johnson et al., (2007) reported that most definitions specify the mixing stage. For example, Axinn \& Pearce (2006) centered on data collection, Tashakkori \& Creswell's (2007) definition included most stages, and O'Cathain, Murphy, \& Nicholl (2007) showed that different stages in a study-design, sampling, analysis, and interpretation-can benefit from MMR. The diversity of definitions is of concern to MMR methodologists because homogeneity in definitions helps establish the approach. Johnson et al., (2007), on the other hand, maintained that heterogeneity should be valued because of the diversity among MMR researchers and projects.

"What is MMR?" is not the only challenge and open question at the center of discussions among MMR scholars. Other questions range from epistemological questions to highly practical matters associated with the actual implementation of the approach. This broad range of questions motivated Tashakkori \& Teddlie (2003c) to develop a typology of MMR questions. Some of their categories are used here to sketch an introduction of a few examples of open questions in MMR.

\section{Methodological considerations}

Like other interpretive approaches, DA combines the recording and transcribing of naturally occurring interactions with ethnographic techniques of observation and interviewing. The initial period of ethnographic research identifies the communicative ecology of a particular setting; for example, the identity of participants (e.g. ethnicity, age, gender), what gets talked about (e.g. flow of topics) and in what ways (e.g. tone of voice, directness). Speakers bring to interaction ideologies, values and beliefs about how people are categorized and these feed into the ways in which participants are treated and decisions are made, without necessarily being explicitly displayed in the interaction. For this reason, it is important to understand the local circumstances and the wider discourses that circulate in the organization before recording and interpreting discourse data.

As a result of these initial ethnographic insights, and with the initial problem in mind, key interactions are audio- or video-recorded. The first stage in analyzing the data is the repeated listening to or viewing of these recordings. This leads to identifying the phases of the interaction that make up the whole. Distinct phases are identified by examining the content, the prosodic cues (including intonation, rhythm, pausing), non-verbal cues and other markers that research in the interactional sociolinguistic tradition has shown people rely on to make inferences.

The second stage of the analysis involves transcribing the data (with line or turn numbers), using transcription conventions at different levels of fineness depending on the features of difference between participants and our own thematic focus (see Appendix). The next stage is to go back to the whole interaction, examine its outcomes and, wherever possible, gain feedback from participants on their interpretation of the events. The final stage of the analysis involves a process of constant reading and re-reading of transcripts, informed by linguistic, sociological and cultural concepts that include those described below. This then leads either to case studies of whole interactions, or comparative analysis of distinct phases of interaction across a larger amount of data.

Negotiating cultural differences in genres would then be an expected part of writing for writers from one culture seeking to communicate with members of another culture. That genre expectation varies not only from genre to genre but also from culture to culture has important ramifications on the growing field of corpus linguistics. The goal of corpus linguistics is to investigate the way people use language by analyzing large databases of real language examples (Biber, Conrad \& Reppen, 1998). However, most current language 
corpora are eclectic collections of spoken and written text from a wide variety of nativelanguage contexts. Although many of these corpora are quite large and much can be discerned about the general lexical and grammatical features of a language from them, they offer little insight into the moves or cultural expectations of individual genres that may make up the larger corpus.

Genre analysis argues first of all that attention to writing for specific purposes is crucial since particular tasks require additional strategies beyond general writing ability. Furthermore, knowing the situation, context, and stimulus is important since these may elicit different types of language based on cultural differences in interpreting purpose and genre by native and nonnative speakers of the language. Consequently, we need corpora that are limited to specific genres and that includes the writing requirements and the cultural contexts in which the texts are generated. This is particularly important when looking at the role culture plays in a genre. For example, the subtleties of accommodating one's writing for another culture should be apparent in tightly controlling for genre and purpose in a learner corpus.

In addition to calling for more specificity in applied learner corpus development with regard to situation, context, and stimulus, we will also show how a text-linguistic approach is useful in analyzing the corpus data. As Flowerdew (1998) points out, a great deal of the more applied, corpus-based analyses have focused on the lexicogrammatical patterning of text, producing collocations and lists of fixed phrases; much of this work has centered on the propositional level of texts, with less regard to functional and rhetorical aspects.

For pedagogical purposes, these general patterns and lists are not always beneficial. For example, instead of producing simple lists of modals and hedges frequently used in English, it may be pedagogically more beneficial to show how these models and hedges are used persuasively in, say, an application letter when politely indicating a desire for an interview - which is an application letter genre move.

\section{Conclusion}

The focus on political contention within broader issue or policy fields, or which focus on the claims-making of a particular category of actors, we have shown that our approach, which seeks to combine the strengths of protest event analysis with those of frame and discourse analysis, can provide important analytic insights that the other alternatives cannot. We believe that by situating protest and social movements not just theoretically, but also methodologically in a wider context of political claims-making, we are in a better position to follow the recent calls for more integrated approaches, which place protest within multiorganizational fields, link it to political opportunities and outcomes, and are sensitive to its discursive message.

\section{References}

Ahl, F. (2007). Aeneid. Oxford University Press.

Ahl, H., \& Nelson, T. (2015). How policy positions women entrepreneurs: A comparative analysis of state discourse in Sweden and the United States. Journal of Business Venturing, 30(2), 273-291. https://doi.org/10.1016/j.jbusvent.2014.08.002

Aijmer, K., \& Simon-Vandenbergen, A. M. (2003). The discourse particle well and its equivalents in Swedish and Dutch. Linguistics, 41(6; ISSU 388), 1123-1162. https://doi.org/10.1515/ling.2003.036

Aijmer, K., \& Simon-Vandenbergen, A. M. (2004). A model and a methodology for the study of pragmatic markers: the semantic field of expectation. Journal of pragmatics, 36(10), 1781-1805. https://doi.org/10.1016/j.pragma.2004.05.005

Axinn, W. G., \& Pearce, L. D. (2006). Mixed method data collection strategies. Cambridge University Press. 
Baker, F. B., \& Kim, S. H. (2004). Item response theory: Parameter estimation techniques. CRC Press. https://doi.org/10.1201/9781482276725

Baker, P. (2006). Using corpora in discourse analysis. A\&C Black.

Bateson, G. (1973). The Logical Categories of Learning and Communication, In, Bateson, 1973. Steps to an Ecology of Mind, 250-79.

Biber, D., Douglas, B., Conrad, S., \& Reppen, R. (1998). Corpus linguistics: Investigating language structure and use. Cambridge University Press.

Chafe, W. (1986). Evidentiality in English conversation and academic writing. Evidentiality: The linguistic coding of epistemology, 20, 261-273.

Chafe, W. (1986). Writing in the perspective of speaking. Ch. Cooper y S. Greenbaum, Studying Writing: Linguistic Approaches, Beverly Hills, sAge Publications.

Chafe, W. L., \& Nichols, J. (Eds.). (1986). Evidentiality: The linguistic coding of epistemology (Vol. 20). Norwood^ eNJ NJ: Ablex Publishing Corporation.

Chafe, W. L., \& Nichols, J. (Eds.). (1986). Evidentiality: The linguistic coding of epistemology (Vol. 20). Norwood^ ${ }^{\wedge}$ eNJ NJ: Ablex Publishing Corporation.

Coffin, C., \& O'Halloran, K. (2008). Researching argumentation in educational contexts: new directions, new methods. https://doi.org/10.1080/17437270802416582

Dobuzinskis, L. (1992). Is progressive environmentalism an oxymoron?. Critical Review, 6(2-3), 283-303. https://doi.org/10.1080/08913819208443266

Dobuzinskis, L. (1992). Modernist and postmodernist metaphors of the policy process: Control and stability vs. chaos and reflexive understanding. Policy Sciences, 25(4), 355380. https://doi.org/10.1007/BF00138019

Doloreux, D., \& Parto, S. (2005). Regional innovation systems: Current discourse and unresolved issues. Technology in society, 27(2), 133-153. https://doi.org/10.1016/j.techsoc.2005.01.002

Donati, P. R. (1992). Political discourse analysis. Studying collective action, 136-167.

Dyson, B. P. (2002). Focus on learnable form in a communicative context. Australian Review of Applied Linguistics, 25(1), 53-70. https://www.jbeplatform.com/content/journals / 18337139

Elmore, R. F., \& McLaughlin, M. W. (1981). Reform and Retrenchment.

Fairclough, N. (2000). Discourse, social theory, and social research: The discourse ofwelfare reform. Journal of sociolinguistics, 4(2), 163-195. https://doi.org/10.1111/1467-9481.00110

Fairclough, N. (2007). Language and globalization. Routledge.

Fairhurst, G. T., \& Uhl-Bien, M. (2012). Organizational discourse analysis (ODA): Examining leadership as a relational process. The Leadership Quarterly, 23(6), 10431062. https://doi.org/10.1016/j.leaqua.2012.10.005

Fetzer, A., \& Johansson, M. (2010). Cognitive verbs in context: A contrastive analysis of English and French argumentative discourse. International journal of corpus linguistics, 15(2), 240-266.

Fidel, R. (2008). Are we there yet?: Mixed methods research in library and information science. Library \& Information Science Research, 30(4), 265-272. https://doi.org/10.1016/j.lisr.2008.04.001

Flowerdew, J. (1997). The discourse of colonial withdrawal: A case study in the creation of $\begin{array}{llll}\text { mythic discourse. Discourse } \quad \& \quad \text { Society, 8(4), } & \text { 453-477. }\end{array}$ https://doi.org/10.1177\%2F0957926597008004002

Flowerdew, J. (1998). The final years of British Hong Kong: The discourse of colonial withdrawal. Springer.

Flowerdew, L. (1998). A cultural perspective on group work. https://doi.org/10.1093/elt/52.4.323

Flowerdew, L. (1998). Corpus linguistic techniques applied to textlinguistics. System, 26(4), 541-552. https://doi.org/10.1016/S0346-251X(98)00039-6

Foucault, M. (1972). The archaeology of knowledge (AMS Smith, Trans.). New York: Pantheon.

Foucault, M. (1972). The archaeology of knowledge, trans. AM Sheridan Smith (New York: Pantheon, 1972), 24. 
Foucault, M. (1972). The confession of the flesh. Power/knowledge: Selected interviews and other writings, 1977, 194-228.

Foucault, M. (1972). The archaeology of knowledge: Translated from the french by AM Sheridan Smith. Pantheon Books.

Gamson, W. A. (1988). Political discourse and collective action. International social movement research, 1(2), 219-244.

Gamson, W. A. (1988). The 1987 distinguished lecture: A constructionist approach to mass media and public opinion. Symbolic interaction, 11(2), 161-174. https://doi.org/10.1525/si.1988.11.2.161

Gamson, W. A., \& Modigliani, A. (1989). Media discourse and public opinion on nuclear power: A constructionist approach. American journal of sociology, 95(1), 1-37.

Gamson, W. A., Gamson, W. A. G., Gamson, W. A., \& Gamson, W. A. (1992). Talking politics. Cambridge university press.

Gitlin, T. (1980). The world is watching: Mass media in the making and unmaking of the new left.

Hardt-Mautner, G. (1995). "How Do We Become Good Europeans?": The British Press and European Integration. Discourse \& Society, 6(2), 177-205.

Hardt-Mautner, G. (1995). How does One Become a Good European?': The British Press and European Integration. Discourse \& Society, 6(2), 177-205. https:/ / doi.org/ 10.1177\%2F0957926595006002003

Hardt-Mautner, G. (1995). Only connect: Critical discourse analysis and corpus linguistics, UCREL technical paper 6. Lancaster: University of Lancaster.

Hardt-Mautner, G. (1995). " Only Connect": Critical Discourse Analysis and Corpus Linguistics. Lancaster: UCREL.

Harris, W. E. (1996). VizieR Online Data Catalog: Globular Clusters in the Milky Way (Harris, 1996). VizieR Online Data Catalog, 7195.

Héritier, A. (2001). Market integration and social cohesion: the politics of public services in European regulation. Journal of European Public Policy, 8(5), 825-852. https://doi.org/10.1080/13501760110083536

Holmes, J. S. (1988). The future of translation theory: a handful of theses. James S. Holmes (1988). Translated. Amsterdam: Rodopi, 97-102.

Hu, G., \& Cao, F. (2011). Hedging and boosting in abstracts of applied linguistics articles: A comparative study of English-and Chinese-medium journals. Journal of pragmatics, 43(11), 2795-2809. https://doi.org/10.1016/i.pragma.2011.04.007

Johnson, M. (2007). The meaning of the body. In Developmental perspectives on embodiment and consciousness (pp. 35-60). Psychology Press.

Jørgensen, W. (2002). Marianne; and Phillips.

Koller, V., \& Mautner, G. (2004). Computer applications in critical discourse analysis.

Kovács, A., \& Wodak, R. (2003). 'Preface'. NATO, Neutrality and National Identity: The Case of Austria and Hungary, Vienna: Böhlau Verlag, 7-22.

Krishnamurthy, T. N. (1996). U.S. Patent No. 5,508,043. Washington, DC: U.S. Patent and Trademark Office.

Laird, A. (1999). Powers of expression, expressions of power: speech presentation and Latin literature. Clarendon Press.

Leech, G. (1992). Corpora and theories of linguistic performance. Directions in corpus linguistics, 105-122.

Magalhães, R. F. (2006). Instrumental action and rhetoric: rebuilding rational action on linguistic field. In Trabalho apresentado no XVIII International Sociological Association World Congress, Yokohama (pp. 13-19).

Mautner, G. (2005). The entrepreneurial university: A discursive profile of a higher education buzzword. Critical discourse studies, 2(2), 95-120. https://doi.org/10.1080/17405900500283540

Mertz, E., \& Yovel, J. (2010). Metalinguistic awareness. Kluwer.

Mur-Dueñas, P. (2011). An intercultural analysis of metadiscourse features in research articles written in English and in Spanish. Journal of pragmatics, 43(12), 3068-3079. https://doi.org/10.1016/j.pragma.2011.05.002 
Ochs, E. (1996). Linguistic resources for socializing humanity. Cambridge University Press.

O'Halloran, K., \& Coffin, C. (2004). Checking over-interpretation and under-interpretation: help from corpora in critical linguistics. Text and texture: systemic functional viewpoints on the nature and structure of text, 275-297. Coffin, C., \& O'Halloran, K. (2006). The role of appraisal and corpora in detecting covert evaluation. Functions of language, 13(1), 77-110. https://doi.org/10.1075/fol.13.1.04cof

Quirk, R., \& Widdowson, H. G. (Eds.). (1985). English in the world: teaching and learning the language and literatures: papers of an International Conference entitled" Progress in English studies" held in London, 17-21 September 1984 to celebrate the Fiftieth Anniversary of the British Council and its contribution to the field of English studies over fifty years. Cambridge University Press for the British Council.

Radaelli, C. M. (2003). The Europeanization of public policy. The politics of Europeanization, 320.

Radaelli, C. M. (2003). The Open Method of Coordination: A new governance architecture for the European Union?. Swedish Institute for European Policy Studies.

Schmidt, V. A. (2002). Europeanization and the mechanics of economic policy adjustment. Journal of European Public Policy, 9(6), 894-912. https://doi.org/10.1080/1350176022000046418

Silverstein, M. (1993). Metapragmatic discourse and. Reflexive language: Reported speech and metapragmatics, 33.

Simon-Vandenbergen, A. M. (1996). Image-building through modality: the case of political interviews. Discourse \& Society, 7(3), 389-415. https://doi.org/10.1177\%2F0957926596007003005

Simon-Vandenbergen, A. M., \& Aijmer, K. (2002). The expectation marker of course in a cross-linguistic perspective. Languages in Contrast, 4(1), 13-43. https://doi.org/10.1075/lic.4.1.03sim

Soler, V. (2002). Analysing adjectives in scientific discourse: an exploratory study with educational applications for Spanish speakers at advanced university level. English for Specific Purposes, 21(2), 145-165. https://doi.org/10.1016/S0889-4906(00)00034-X

Stubbs, M. (1994). Grammar, text, and ideology: computer-assisted methods in the linguistics of representation. Applied Linguistics, 15(2), 201-223. https://doi.org/10.1093/applin/15.2.201

Stubbs, M. (1997). Whorf's children: Critical comments on critical discourse analysis (CDA). British studies in applied linguistics, 12, 100-116.

Tashakkori, A., \& Creswell, J. W. (2007). The new era of mixed methods. Tashakkori, A., \& Creswell, J. W. (2007). Exploring the nature of research questions in mixed methods research.

Teddlie, C., \& Tashakkori, A. (2003). Major issues and controveries inthe use of mixed methods in the social and behvioral sciences. Handbook of mixed methods in social \& behavioral research, 3-50.

Upton, T. A., \& Connor, U. (2001). Using computerized corpus analysis to investigate the textlinguistic discourse moves of a genre. English for Specific Purposes, 20(4), 313-329. https://doi.org/10.1016/S0889-4906(00)00022-3

Verschueren, J. (2000). Understanding pragmatics.

White, H. (2000). A reality check for data snooping. Econometrica, 68(5), 1097-1126. https://doi.org/10.1111/1468-0262.00152

White, L., \& White, L. (2003). Second language acquisition and universal grammar. Cambridge University Press.

Wodak, R. (1990). The Waldheim affair and antisemitic prejudice in Austrian public discourse. Patterns of Prejudice, 24(2-4), 18-33. https://doi.org/10.1080/0031322X.1990.9970049

Wodak, R., \& Meyer, M. (2009). Critical discourse analysis: History, agenda, theory and methodology. Methods of critical discourse analysis, 2, 1-33.

Wood, L. A., \& Kroger, R. O. (2000). Doing discourse analysis: Methods for studying action in talk and text. Sage. 
Zurcher, L. A., \& Curtis, R. L. (1973). A comparative analysis of propositions describing social movement organizations. Sociological Quarterly, 14(2), 175-188. https://doi.org/10.1111/j.1533-8525.1973.tb00852.x 